\title{
Postoperative Shoulder Pain after Laparoscopic Surgery
}

\author{
Sun Jin Park, M.D., Ph.D. \\ Department of Surgery, Kyung Hee University College of Medicine, Seoul, Korea
}

We often encounter patients complaining of shoulder pain after laparoscopic surgery. The pain mechanism is believed to be due to the diaphragmatic overstretching under pressure in a pneumoperitoneum, which causes referred pain to the shoulder, but the exact mechanism has not been clarified.

Keywords: Laparoscopy, Surgery, Shoulder pain, Postoperative pain, Appendectomy
Received February 21, 2020

Revised February 25, 2020

Accepted February 26, 2020

\author{
Corresponding author \\ Sun Jin Park \\ Department of Surgery, Kyung Hee \\ University Hospital, 26 Kyunghee- \\ daero 23, Dongdaemun-gu, Seoul \\ 02447, Korea \\ Tel: +82-2-958-8241 \\ Fax: +82-2-966-9366 \\ E-mail: gsdrpark@naver.com \\ ORCID: \\ https://orcid.org/0000-0001-7117-4479
}

Copyright $\odot 2020$ The Journal of Minimally Invasive Surgery. All rights reserved.
This is an Open Access article distributed under the terms of the Creative Commons Attribution Non-Commercial License (http:// creativecommons.org/licenses/by-nc/4.0/) which permits unrestricted non-commercial use, distribution, and reproduction in any medium, provided the original work is properly cited.
We often encounter patients complaining of shoulder pain after laparoscopic surgery in clinical practice. The authors conducted a prospective study with curiosities about the clinical situation of shoulder pain after laparoscopic appendectomy. ${ }^{1}$ As a result of a multivariate analysis, low body weight was suggested as the only risk factor of shoulder pain in their study. Actually, we experience many low-weight patients with shoulder pain after laparoscopic surgery. Despite an interesting clinical situation, there were some questions in this study. We did not know what the incidence of shoulder pain was in this study. It would be appropriate to compare patients with and without shoulder pain. Instead, they divided patients into two groups based on the pain score of 4 . They defined a visual analogue score (VAS) of 4 as the minimum pain points as it was reported that VAS scores of 3.5 to 6.4 implied moderate pain in a study. ${ }^{2}$ A receiver operating characteristic (ROC) curve is frequently used to choose the most appropriate cut-off for a test. It would have been better if a threshold pain score was determined first after ROC analysis and then univariate and multivariate analysis were performed.

The incidence of shoulder pain was reported by $63 \%$ after laparoscopic cholecystectomy, ${ }^{3}$ 66\% after laparoscopic gastric band surgery, ${ }^{4}$ and $83 \%$ after gynecological laparoscopic surgery. ${ }^{5}$ Although the exact mechanism of shoulder pain after laparoscopic surgery has not been clarified, a leading hypothesis is that excessive stretching of the diaphragm due to the pressure of a pneumoperitoneum, which results in phrenic nerve-mediated referred pain to the shoulder. ${ }^{6-8}$ Shin et al. evaluated whether mechanical ventilation with a low tidal volume (LTV, $7 \mathrm{ml} / \mathrm{kg}$ ) might reduce shoulder pain in patients undergoing laparoscopic appendectomy compared with ventilation with the traditional tidal volume (TTV, $10 \mathrm{ml} / \mathrm{kg}$ ). 
However, the overall incidence of shoulder pain was similar in both groups (57.1\% in LTV group vs. $65.5 \%$ in TTV group). The pain score did not decrease in the LTV group compared with the TTV group. They concluded that mechanical ventilation with a LTV of $7 \mathrm{ml} / \mathrm{kg}$ does not reduce the frequency and severity of shoulder pain after laparoscopic appendectomy compared with ventilation with a TTV of $10 \mathrm{ml} / \mathrm{kg}$. A randomized controlled trial with 116 patients demonstrated that shoulder pain as well as postoperative nausea and vomiting was effectively reduced by a simple clinical maneuver of removing residual intra-abdominal carbon dioxide before clos $^{-}$ ing the laparoscopic wounds.

\section{ORCID}

Sun Jin Park, https://orcid.org/0000-0001-7117-4479

\section{CONFLICT OF INTEREST}

None.

\section{FUNDING}

None.

\section{ACKNOWLEDGMENTS}

None.

\section{REFERENCES}

1) Kim BM, Kim JB, Park IS, et al. Unmodifiable clinicopathological risk factors of shoulder tip or subcostal pain after laparoscopic appendectomy. J Minim Invasive Surg 2020;23:43-48.

2) Boonstra AM, Schiphorst Preuper HR, Balk GA, Stewart RE. Cutoff points for mild, moderate, and severe pain on the visual analogue scale for pain in patients with chronic musculoskeletal pain. Pain 2014;155:2545-2550.

3) Chang SH, Lee HW, Kim HK, Kim SH, Kim DK. An evaluation of perioperative pregabalin for prevention and attenuation of postoperative shoulder pain after laparoscopic cholecystectomy. Anesth Analg 2009;109:1284-1286.

4) Dixon JB, Reuben $Y$, Halket C, O'Brien PE. Shoulder pain is a common problem following laparoscopic adjustable gastric band surgery. Obes Surg 2005;15:1111-1117.

5) Phelps P, Cakmakkaya OS, Apfel CC, Radke OC. A simple clinical maneuver to reduce laparoscopy-induced shoulder pain: a randomized controlled trial. Obstet Gynecol 2008;111:1155-1160.

6) Berberoğlu M, Dilek ON, Ercan F, Kati I, Ozmen M. The effect of $\mathrm{CO} 2$ insufflation rate on the postlaparoscopic shoulder pain. J Laparoendosc Adv Surg Tech A 1998;8:273-277.

7) Mouton WG, Bessell JR, Otten KT, Maddern GJ. Pain after laparoscopy. Surg Endosc 1999;13:445-448.

8) Sarli L, Costi R, Sansebastiano G, Trivelli M, Roncoroni L. Prospective randomized trial of low-pressure pneumoperitoneum for reduction of shoulder-tip pain following laparoscopy. Br J Surg 2000;87:1161-1165.

9) Shin HY, Kim SH, Lee YJ, Kim DK. The effect of mechanical ventilation tidal volume during pneumoperitoneum on shoulder pain after a laparoscopic appendectomy. Surg Endosc 2010;24: 2002-2007. 